\title{
Editorial
}

Dermatology 2005;211:77-78

DOI: $10.1159 / 000086431$

\section{Consensus Statement on the Safety Profile of Topical Calcineurin Inhibitors}

\author{
T. Bieber ${ }^{\mathrm{a}}$ M. Cork ${ }^{\mathrm{b}} \quad$ C. Ellis ${ }^{\mathrm{c}} \quad$ G. Girolomoni ${ }^{\mathrm{d}}$ \\ R. Groves ${ }^{\text {e R. Langley }}{ }^{f}$ \\ T. Luger ${ }^{9}$ \\ M. Meurer ${ }^{\mathrm{h}}$ \\ D. Murrelli \\ S. Orlow ${ }^{j}$ \\ A. Paller ${ }^{k}$ Y. de Prost ${ }^{\prime}$ \\ L. Puigm \\ J. Ring ${ }^{\mathrm{n}}$ J.-H. \\ H. Saurat ${ }^{\mathrm{O}} \quad$ T. Schwarz ${ }^{p}$ \\ N. Shear ${ }^{q}$ \\ G. Sting $\left.\right|^{r}$
}

A. Taieb ${ }^{s}$ K. Thestrup-Pedersen ${ }^{t}$

\begin{abstract}
a University of Bonn, Bonn, Germany; ${ }^{b}$ University of Sheffield Medical School \& Sheffield Children's Hospital, Sheffield, UK; ${ }^{c}$ University of Michigan Medical School, Ann Arbor, Mich., USA; ${ }^{d}$ University of Verona, Verona,

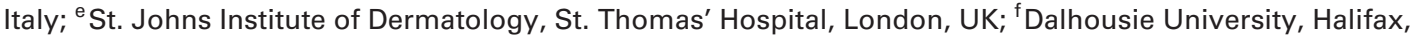
Canada; ${ }^{9}$ University of Münster, Münster, and ${ }^{\mathrm{h}}$ Dresden University of Technology, Dresden, Germany; iSt George Hospital, University of New South Wales, Sydney, Australia; 'NYU School of Medicine, New York, N.Y., and k Northwestern University's Feinberg School of Medicine, Chicago, III., USA; 'Hôpital Necker-Enfants Malades, Paris, France; ${ }^{\mathrm{m}}$ Hospital Santa Creu i Sant Pau, Barcelona, Spain;

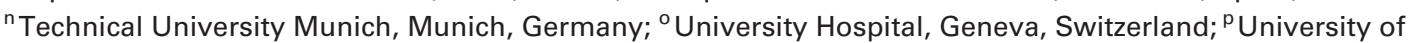
Kiel, Kiel, Germany; ${ }^{q}$ University of Toronto, Toronto, Canada; ${ }^{r}$ Medical University of Vienna, Vienna, Austria; ${ }^{\mathrm{s}}$ Central Hospital, University of Bordeaux, Bordeaux, France; ${ }^{\mathrm{t}}$ Aarhus University Hospital, Aarhus, Denmark
\end{abstract}

On February 15, 2005, the Pediatric Advisory Committee of the Food and Drug Administration (FDA) recommended 'black box' warnings for pimecrolimus cream $\left(\right.$ Elidel $^{\circledR}$ ) and tacrolimus ointment $\left(\right.$ Protopic $^{\circledR}$ ) because of concerns of potential safety risks (including skin cancer and lymphoma). On March 10, 2005, the FDA issued a Public Health Advisory informing health-care providers of the Agency's safety concerns associated with use of these drugs. We are deeply troubled by the FDA's actions, because there is no evidence that topical use of pimecrolimus and tacrolimus causes malignancies.

Over the last decade, both agents have been extensively studied in clinical trials involving almost 40,000 patients, and their efficacy and safety in the treatment of atopic dermatitis have been demonstrated. More than 7.5 million patients, over half of them children, have been treated with these medications since their approval.

Systemic absorption of both drugs is very limited and even though blood concentrations have been detected in some patients, the values are usually very low and insuf- ficient to cause the sustained systemic immunosuppression that would be responsible for lymphomas [1]. This is true even in young children with moderate-to-severe dermatitis affecting a large body surface area [2].

There is no evidence of photocarcinogenic or mutagenic potential in animals treated with pimecrolimus. Neither pimecrolimus nor tacrolimus have been associated with an increased risk of malignancies in clinical studies [1].

From clinical use in over 7.5 million patients treated with one or the other medication, very few cases of malignancies have been reported. The number is well below the expected background incidence in the population treated, even taking into account under-reporting [1].

Those lymphomas identified by spontaneous adverseevent reporting systems do not have the clinical presentation and histology that characterize lymphomas occurring in the setting of immunosuppressive therapy. In contrast, lymphomas that have the characteristics of disease related to systemic immunosuppression have only been

\section{KARGER}

Fax +41613061234 E-Mail karger@karger.ch www.karger.com
(C) 2005 S. Karger AG, Basel

$1018-8665 / 05 / 2112-0077 \$ 22.00 / 0$

Accessible online at: www.karger.com/drm
Thomas Luger, MD, Professor and Chairman

University Clinics Münster, Department of Dermatology

Von-Esmarch-Str. 58

DE-48149 Münster (Germany)

Tel. +49 251835 6504, Fax +49 251835 6522, E-Mail derma@uni-muenster.de 
observed in animals exposed to high systemic levels of calcineurin inhibitors. These animals experienced systemic exposure that is much greater than can be achieved with topical application in humans [1].

There is no increased incidence of systemic infections in patients treated with topical calcineurin inhibitors [1].

There is no evidence of systemic immunosuppression from topical pimecrolimus or tacrolimus as measured by response to vaccination and delayed-type hypersensitivity [3-5].

Atopic dermatitis is a chronic, recurring and frustrating condition. Many patients suffer from atopic dermatitis on the face and sensitive skin sites where long-term application of topical corticosteroids is not indicated.
The health and safety of patients are of paramount importance to physicians. We are concerned that the aforementioned warnings confuse and unnecessarily worry patients and their families, as well as health-care providers. Current labeling sufficiently describes the appropriate use and safety of these medications. We strongly believe that the recent recommendations of the Pediatric Advisory Committee and the FDA Health Alert are not justified based on the scientific evidence and should be reconsidered.

\section{Acknowledgment}

The Consensus Statement was developed at a meeting supported by Novartis Pharma AG, Basel, Switzerland.

\section{References}

1 Food and Drug Administration Pediatric Advisory Committee. February 15, 2005, Briefing Information. http://www.fda.gov/ohrms/ dockets/ac/05/briefing/2005-4089b2.htm

2 Allen BR, Lakhanpaul M, Morris A, Lateo S, Davies T, Scott G, Cardno M, Ebelin ME, Burtin P, Stephenson TJ: Systemic exposure, tolerability and efficacy of pimecrolimus cream 1\% in atopic dermatitis patients. Arch Dis Child 2003;88:969-973.
3 Wahn U, Bos JD, Goodfield M, Caputo R, Papp K, Manjra A, Dobozy A, Paul C, Molloy S, Hultsch T, Graeber M, Cherill R, de Prost $\mathrm{Y}$, and the Flare Reduction in Eczema with Elidel (Children) Multicenter Investigator Study Group: Efficacy and safety of pimecrolimus cream in the long-term management of atopic dermatitis in children. Pediatrics 2002; 110:e2.
4 Papp KA, Breuer K, Meurer M, Ortonne JP, Potter PC, de Prost Y, Davidson MJ, Barbier N, Goertz HP, Paul C: Long-term treatment of atopic dermatitis with pimecrolimus cream $1 \%$ in infants does not interfere with the development of protective antibodies after vaccination. J Am Acad Dermatol 2005;52:247-253.

5 Stiehm ER, Roberts RL, Kaplan MS, Corren $\mathrm{J}$ : Tacrolimus ointment does not alter immune responses of eczematous children. J Allergy Clin Immunol 2003;111:S355. 